\title{
A INFLUÊNCIA DA ÊPOCA DE SELEÇÃO DO REBENTO SOBRE O DESENVOLVIMENTO DAS PLANTAS MATRIZES EM BANANEIRA MUSA CAVENDISHII LAMB. CV NANICÃO *
}

\author{
Freddy P. Zambrano Perez \\ Salim Simão $* * *$ \\ Ivo MANICA $* * * *$
}

\section{RESUMO}

\begin{abstract}
As mudas utilizadas no experimento foram plantadas em setembro de 1971, sendo cinco os tratamentos: planta matriz sem rebento, planta matriz com seleção dos rebentos, de janeiro, março e maio de 1972 e planta matriz com todos os rebentos.

Os resultados obtídos revelam influência da época da seleção dos rebentos sobre: diâmetro do pseudo-caule e lançamento de folhas no mês de abril, durante a fase de desenvolvimento vegetativo; número de dias decorridos do plantio ao florescimento, número de plantas florescidas no mês de julho, número de folhas, altura e diâmetro do pseudo-caule, número de pencas por cacho e altura do rebento na fase do florescimento.
\end{abstract}

\section{INTRODUÇÃO}

A bananeira é planta pertencente à classe das monocotiledoneas, família Musaceae, a qual contém de 31 a 36 espécies distribuídas em dois gêneros: Ensete e Musa.

O gênero Musa possue quatro secções das quais Australimusa e Eumusa são as que apresentam frutas, tendo a segunda maior importância econômica. As espécies produtoras de frutos pertenocárpicos e estéreis sugiram do cruzamento entre duas espécies selvagens, Musa acuminata Colla e Musa balbisiana Colla, segundo SIMMONDS (1964).

* Parte da dissertação do primeiro autor apresentada a E. S. A. «Luiz de Queiroz», como uma das exigências para a obtenção do título de Mestre. Entregue para publicação em 21/12/1973.

** Escola de Agronomia - Universidade Centro Ocidental - Venezuela.

*** Departamento de Agric. e Horticultura - ESALQ - Piracicaba.

**** Departamento de Fitotecnia - Universidade Federal de Vicosa. 
Seu ciclo completo do plantio à colheita, varia com as condições ambientais e tratos culturais, sendo no Litoral do Estado de São Paulo, segundo SAMPAIO (1967) e MATTOS (1969) de 13 a 15 meses.

E prática comum, em expiorações econômicas, conduzir o bananal com uma planta matriz e apenas um rebento, quase sempre o primeiro que se forma, sendo os demais eliminados sistematicamente, pela prática do desbaste.

Como a seleção do rebento varia de acordo com a época de plantio, fatores edáficos e climáticos, um bananal produz cachos o ano todo no Estado de São Paulo, mas não com igual intensidade, correndo acúmulo de produção nos meses de janeiro a julho e escassez de agosto a dezembro. A estas flutuações de produção correspondem épocas de preços altos e baixos, resultantes principalmente de oscilações na of erta da banana considerando-se a demanda estável.

Este trabalho estuda a influência da época de seleção do rebento sobre o desenvolvimento das plantas matrizez, de bananeiras, Musa cavendishii Lamb. cv. Nanicão.

\section{REVISÃO DE LITERATURA}

As bananeiras propagam-se vegetativamente, caracterizando-se segundo DE LANCHE (1961), BAHKER e STEWARD (1962), por apresentarem estrutura monopodial, em que o rizoma é o caule principal, e pelo desenvolvimento de suas gemas adventícias que se transformarão em rebentos.

BAXTER, citado por KERVEGANT (1935), trabalhando na Jamaica com o cultivar «Gros Michel», diz que o desbaste tem como objetivo selecionar os rebentos nas diferentes épocas do ano e obter plantas cujas colheitas ocorram nos meses de mais alto preço, antes do período dos ciclones, muito comuns naquele país.

KERVEGANT (1935) afirma que um dos principais objetivos do desbaste é regular a época de coiheita. Explica que a técnica de selecionar rebentos que frutifiquem em períodos favoráveis é muito delicada, pois o ciclo da planta da brotação à colheita, varia conforme uma série de parametros principalmente clima, solo e exposição.

RODRIGUES E SOUZA (1947), estudando no cultivar «Nanica» a época de seleção do rebento, seu desenvolvimento e frutificação, na Ilha da Madeira, encontraram dois fatores intervindo na distribuição das colheitas pelos diferentes meses do ano: o mes de seleção do rebento e a duração do período de atividade vegetativa.

BHAN e MAZUNDER (1958), BERRILL (1960) e ROCHA e FRANCIOSI (1963), em trabalhos efetuados no Oeste de Bengala, na Estação Experimental de Marrochy e no Peru, respectivamente, com diferentes materiais de propagação, não encontraram diferença significativa entre os mesmos, para rendimento. MOREZ (1960), MOREZ e GUILLEMOT (1961) e CHAMPION (1962), em Guadalupe e Jamaica, concluiram que o desenvolvimento e a 
precocidade dos rebentos eram dependentes da porção do pseudo-caule da planta matriz deixado por ocasião da eliminação da mesma, depois da colheita do cacho.

Sabe-se que para o desenvolvimento normal da bananeira o clima deve ser favorável, nem todas as áreas em exploração apresentando condições climáticas ideais. TRELEASE (1923) nas Filipinas, observou um crescimento médio de $9.2 \mathrm{~cm}$ durante o período diurno e $14,4 \mathrm{~cm}$ para o período noturno, em folhas de bananeira. Concluiu-se que o aumento do crescimento das folhas está relacionado com condições (umidade e temperatura) e condições intrínsecas da própria planta (vigor e fase de desenvolvimento). KERVEGANT (1935), observou uma heterogeneidade na conformação dos cachos nos cones «Nanica»e «Nanicão», na Martinica, concluindo serem tais caracteres hereditarios ou devidos ao meio ambiente.

SMIRIM (1960) observando a cultura da bananeira em Israel, afirma que a possibilidade de atingir rendimentos altos e estáveis depende da época da emissão da inflorescência, limitando-se a um curto período durante o verão.

BARKER (1961) em estudos sobre o crescimento vegetativo do cultivar «Gros Michel» na América Central, constatou que dependendo das condições climáticas, a inflorescência aparece quando a altura do pseudo-caule é de 3 a $6 \mathrm{~m}$ e a emissão foliar de aproximadamente 40 folhas .

CORTEZ (1961), trabalhando no Litoral do Estado de São Paulo, Brasil, com o cultivar «Nanica», constata que a qualidade da fruta (número de pencas, peso e formação) depende do período em que ocorre a diferenciação floral e o florescimento.

Com relação às exigências climáticas da bananeira, CHAMPION (1963), afirma que a atividade vegetativa da planta é fortemente reduzida quando a temperatura baixa para $16^{\circ} \mathrm{C}$. Considera a temperatura de $25^{\circ} \mathrm{C}$ ideal para um desenvolvimento normal, estimando pluviosidade mensal satisfatória de 120 a $150 \mathrm{~mm}$.

ARSCOTT et alii (1965) estudando, em Honduras, os efeitos do clima (temperatura e umidade) em duas épocas diferentes sobre o consumo diário de água e o desenvolvimento do cultivar «Nanicão», concluiram que, quando a fase de desenvolvimento maior coincidia com baixas temperaturas e alta umidade relativa $\left(21^{\circ} \mathrm{C}\right.$ e $86 \%$ U. R.) o crescimento era reduzido e o período entre a omissão da inflorescência e a colheita aumentava. Nas plantas em que o cacho era produzido durante a estação seca $\left(28^{\circ} \mathrm{C}\right.$ e $63 \%$ U. R.), as folhas apresentavam-se dessecadas e os frutos amadureciam antes de atingir o ponto de colheita.

Observando as influências do clima sobre a cultura da bananeira na Guiné Francesa, CHAMPION (1951), verifica que a existência de um prolongado período seco, temperaturas com um mínimo inferior a $12^{\circ} \mathrm{C}$ e variações extremas na umidade relativa, limitam a exploração econômica da bananeira. Constata que a planta deve emitir um total de 25 a 30 folhas até a emissão da inflorescência e considera necessárias no mínimo 15 folhas para um desenvolvimento normal e boa frutificação. 
Trabalhando em Honduras e na Costa Rica, com o cultivar «Gros Michel», BARKER (1969) verificou que o máximo de crescimento das folhas ocorre com altas temperaturas e baixas porcentagens de umidade relativa, até determinado limite. Observou que com temperaturas altas $\left(32^{\circ}\right.$ a $\left.35^{\circ} \mathrm{C}\right)$ havia uma paralização temporária do crescimento.

AUBERT (1971), observando a ação do clima sobre a bananeira nas zonas tropicais que a produção pode ser ajustada em função das condições climáticas e econômicas de três maneiras: seleção do material de plantio, desbaste dos rebentos e época do plantio, sendo que esta última não é aceitável para as zonas subtropicais, onde o plantio é efetuado somente na primavera.

TURNER (1971) estudando os ef eitos do clima sobre o cultivar «Willians», em Alstonville, observou que a produção de folhas aumentava com a elevação da temperatura, vento e umidade, fatores intimamente ligados, sendo difícil separar seu efeito individual, ainda que temperatura parecesse constituir o principal fator limitante.

WARDLAW (1933) em estudo realizado no Brasil, verificou que o inverno não só afetava o crescimento como também prejudicava o rendimento $\mathrm{e}$ a qualidade do fruto.

KERVEGANT (1935) nas llhas Canárias relata que temperaturas de $7^{\circ}$ e $8^{\circ} \mathrm{C}$ tem sido apontadas como mínimas para diversos cultivares, sendo para os do grupo «Cavendish» de $2^{\circ}$ e $3^{\circ} \mathrm{C}$. Este grupo, apesar de suportar baixas temperaturas tem seu crescimento e produtividade severamente afetados. $\mathrm{O}$ autor afirma que as plantações ao nível do mar tem rendimento maior que as situadas a $400 \mathrm{~m}$ de altitude.

Referindo-se as exigências climáticas da bananeira, WARDLAW (1961), assinalou que a ocorrência de temperatura de $25,5^{\circ} \mathrm{C}$, dois meses antes da colheita aumentava o peso do cacho. Temperaturas mais altas aceleravam a maturação e mais baixas eram prejudiciais ao desenvolvimento do fruto. Explica que bananeiras que crescem em localidades elevadas, podem apresentar «chilling» nos frutos em regiões tropicaís, e em regiōes subtropicais, redução no comprimento do cacho e do verdadeiro caule, e não emissão da inflorescência, em virtude do «choque» causado por baixas temperaturas.

GREEN e KUNHE (1969 e 1970), estudando em Nelspruit (região subtropical), o efeito das variações da temperatura no inverno e no verão, sobre o crescimento do cultivar «Nanica», concluiram que toda a atividade fisiológica cessa com temperaturas inferiores a $11^{\circ} \mathrm{C}$, sendo a temperatura ótima de $30^{\circ} \mathrm{C}$. Afirmam que, para conseguir um máximo de crescimento, é mais importante a elevação de temperatura que um ótimo de umidade no solo.

Estudando a nutrição mineral do cultivar «Nanica» em Trinidad, MURRAY (1960) cita que, dependendo do peso do rebento e das reservas de nutrientes acumulados no rizoma, uma planta pode produzir 12 folhas sem receber nutrientes de fontes externas. Explica que a emissão entre folhas é afetada pelos teores $\mathrm{N}>\mathrm{K}>\mathrm{P}>\mathrm{Ca}>\mathrm{mg}$. 
CHAMPION (1960), afirma que na Guiné o cultivar «Nanica» apresenta constantemente 13,12 folhas ativas durante a época seca e 14,6 folhas no período das chuvas.

Referindo-se a cultura da bananeira em Israel, COMELLI (1960) relata que na região da costa, a planta tem um desenvolvimento vegetativo durante 7 meses. De maio a setembro emite 4 a 5 folhas por mês, de abril a outubro de 2 a 3 folhas e no inverno sua produção é totalmente paralisada.

WARDLAW (1961), afirma que a bananeira produz em condições normais 20 folhas durante os primeiros 6 meses e 15 folhas numa segunda fase, sendo estas responsáveis pela nutrição da inflorescência e dos frutos.

CHAMPION (1961) observando o crescimento do cultivar «Poyo», em Guadalupe e Guiné, concluiu que, dependendo do desenvolvimento inicial do rebento, o número total de folhas era de 23 a 40 ocorrendo aumento da área foliar até a terceira folha, antes do aparecimento da inflorescência.

SIMMONDS (1964) referindo-se ao desenvolvimento da bananeira, considera um total de 60 a 70 folhas emitidas desde o estágio de rebento até 0 aparecimento da inflorescência ocorrendo a emissão de uma folha cada 7 a 10 dias, e sendo mantidos na planta de 10 a 15 folhas verdes.

MARTINEZ (1971) em São Paulo, Brasil, estudou os lançamentos mensais das folhas do cultivar «Nanicão» concluindo que janeiro e julho eram os meses de maior e menor lançamento respectivamente sendo que o período de maior lançamento ocorre entre novembro e março com uma média de 3,21 folhas por mês, e o menor lançamento de abril a outubro, com uma média de 2,0 folhas por mês.

Estudando o crescimento e desenvolvimento da bananeira BARKER e STEWARD (1962) observaram que durante os primeiros estádios o desenvolvimento é muito vigoroso ocorrendo alongamento da folha de aproximadamente $300 \mathrm{~cm}$ em um período de 8 dias, podendo ser verificado aumentos de $2,54 \mathrm{~cm}$ em umá hora.

Efetuando estudos com o cultivar «Gros Michel», HASSELO (1962), observou alta correlação entre a circunferência do pseudo-caule tomada a um metro do solo na floração e o peso do cacho, sendo o coeficiente de correlação de 0,88 a 0,95 .

Em estudo sobre a previsão das colheitas de bananeira, LOSSOIS (1963), demonstrou que existe uma grande correlação entre a circunferência do pseudo-caule, tomada a um metro do solo, na floração e o peso do cacho. 0 coeficiente de correlação foi de 0,68 .

SAMPAIO (1967), no Litoral do Estado de São Paulo, Brasil obteve para o cultivar «Nanicão», 12,1 folhas no florescimento; $2,10 \mathrm{~m}$ de altura da planta; 289,1 dias do plantio ao florescimento; 7,53 pencas por cacho e $16,94 \mathrm{~m}^{2}$ de área foliar.

Ainda no litoral de São Paulo, MATTOS (1969), estudando os aspectos da densidade do bananal para o cultivar «Nanicão» concluiu que para o primeiro ciclo com espaçamento de $3,0 \times 2,0 \mathrm{~m}$, a média para diâmetro do pseudo- 
caule foi de $17,9 \mathrm{~cm}$, para aitura cie $203,0 \mathrm{~cm}$, para o número de folhas de 11,6 e número de pencas por cacho 7,4 .

CORTEZ (1971a,b) estudancio o desenvolvimento dos cultivares «Nanica» e «Nanicão», no Estado de São Paulo, Brasil, concluiu que tanto a fase vegetativa como a frutificação tem um rítmo lento de crescimento de abril a agosto, aumentando a partir de agosto ambos os processos e sendo a época de maior florescimento de fevereiro a agosto.

LASSOUDIERE e CHARPENTIER (1971) estudando na Costa de Marfim o cultivar «Hoyo» observaram que o principal fator limitante do crescimento é o déficit ou excesso hídrico, crescimentos superiores a $14 \mathrm{~cm}$ diários indicando um teor de umidade satisfatório.

BORGES (1971), observou na Venezuela, o comportamento de diferentes cultivares de banana, conseguindo para o cultivar «Nanicão», em média, uma altura de $2,16 \mathrm{~m} ; 215$ dias para a floração e um número de pencas igual a 7 .

\section{MATERIAL E METODOS}

O presente ensaio foi instalado em área do Departamento de Agricultura e Horticultura da Escola Superior de Agricultura «Luiz de Queiroz», em Piracicaba; em solo pertencente, segundo RANZANI et alii (1969) à série «Luiz de Queiroz». O clima da região é mesotérmico, úmido, subtropical, com inverno seco, designado Cwa, segundo o sistema de classificação de Koopen.

A temperatura média do mês mais quente durante o período de ensaio foi de $24,3^{\circ} \mathrm{C}$ e a do mês mais frio de $16,9^{\circ} \mathrm{C}$; a temperatura máxima foi de $30,4^{\circ} \mathrm{C}$ e a mínima de $9,0^{\circ} \mathrm{C}$ : a mínima absoluta, em junho de 1972 , foi de $3,0^{\circ} \mathrm{C}$ e no mês de julho de $0,2^{\circ} \mathrm{C}$.

Foi utilizado, no plantio o cultivar Nanição (Musa cavendishii Lambert) com mudas do tipo «chifre» e peso médio de $2,3 \mathrm{~kg}$. As mudas foram retiradas do bananal e mergulhadas por 1 minuto, numa solução contendo BHC a $5 \%$, sendo posteriormente deixadas secar à sombra durante 6 horas. A área foi arada, gradeada e sulcada de $2,5 \times 2,5 \mathrm{~m}$, com sulcos de $30 \mathrm{~cm}$ de profundidade. Após a sulcagem, foram aplicados $500 \mathrm{~g}$ da fórmula 10-5-20 de NPK por sulco, sendo o adubo misturado com o solo na posição correspondente a cada muda.

As mudas foram plantadas no dia 17 de setembro de 1971 , na distância de 2 metros dentro do sulco, realizando-se em 26/01/72 adubação em cobertura com $250 \mathrm{~g}$ de sulfato de amônio por planta e em $17 / 03 / 1971$, com $500 \mathrm{~g}$ da fórmula 10-5-20 NPK.

As plantas foram irrigadas no início do experimento, em sulcos com intervalos de 7 dias; de maio a agosto as irrigações foram espaçadas de $15 \mathrm{em}$ 15 dias ou feitas 15 dias após as chuvas. A partir ce 25/01/72. as irrigações foram feitas sempre que a porcentagem de água útil do solo atingia $50 \%$.

Durante o decorrer do experimento, foram efetuados os desbastes de rebentos e controle de ervas daninhas. 
0 delineamento experimental foi em blocos inteiramente casualizados com 5 tratamentos e 5 repetições. Cada parcela era composta de 6 plantas úteis, sendo 20 o total de plantas na mesma parcela.

Os tratamentos foram os seguintes:

1. SR - planta matriz sem rebento;

2. RJ -- planta matriz com seleção do rebento do mês de janeiro;

3. RM - planta matriz com seleção do rebento do mês de março;

4. RMa - planta matriz com seleção de rebento do mês de maio ; e

5. T - Testemunha com todos os rebentos presentes.

Semanalmente foram feitas anotações do número de folhas diâmetro do pseudo-caule na época da inflorescência e colheita do cacho, peso, número de pencas e frutos por ocasião da colheita.

Foram coletados dados referentes a diâmetro do pseudo-caule, altura das plantas e número de folhas ativas, área foliar, número total de folhas, número de lançamentos mensais de folhas, florescimentos mensais, número de dias do plantio ao florescimento e número de pencas por cacho.

0 diâmetro do pseudo-caule foi tomado a $20 \mathrm{~cm}$ do solo. A altura do pseudo-caule foi medida do nível do solo até o cruzamento dos pecíolos das últimas duas folhas, de acôrdo com o método de Bouffil, citado por GUYOT e FOUQUE (1954).

0 cálculo da área foliar foi baseado no produto da maior largura pelo comprimento da folha, e pelo fator 0,8 de conformidade com CHAMPION (1963). Para a contagem do número de pencas por cacho, considerou-se apenas aquelas que possuissem no mínimo oito frutos.

\section{RESULTADOS E DISCUSSÃO}

\section{Diâmetro do pseudo-caule}

A análise de variância para diâmetro do pseudo-caule em 8/2/72, mostrou diferença significativa entre tratamentos ao nível de $5 \%$ de probabilidade.

A comparação das médias para diâmetro do pseudo-caule aparece no quadro 1 , revelando diferença significativa ao nível de $5 \%$ de probabilidade, pelo teste de Tukey.

A comparação das médias através do teste de Tukey, mostra que houve diferença significativa entre os tratamentos $3(\mathrm{RM})$ e 4 (RMa). Os tratamentos $3(\mathrm{RM}), 1(\mathrm{SR}), 2$ (RJ) e $5(\mathrm{~T})$, não revelaram diferença significativa entre si. 
Quadro 1 - Comparação das médias dos diversos tratamentos para diâmetro do pseudo-caule em $8 / 2 / 72$.

\begin{tabular}{cc}
\hline Tratamentos & Diâmetro do pseudo-caule $(\mathrm{cm})$ \\
\hline $3(\mathrm{RM})$ & $11,12 \mathrm{a}^{*}$ \\
$1(\mathrm{SR})$ & $10,91 \mathrm{a} \mathrm{b}$ \\
$2(\mathrm{RJ})$ & $10,74 \mathrm{a} \mathrm{b}$ \\
$5(\mathrm{~T})$ & $10,58 \mathrm{a} \mathrm{b}$ \\
$4(\mathrm{RMa})$ & $9,49 \mathrm{~b}$ \\
\hline
\end{tabular}

$\Delta 5 \%=1,52$

(*) Letras diferentes, tratamentos apresentam diferença significativa.

Os resultados obtidos para diâmetro do pseudo-caule no tratamento 4 (RMa) que mostrou menor desenvolvimento em relação ao tratamento 3 (RM), pode ser atribuido ao atraso ocorrido no crescimento de uma das par-. celas, como consequência de ventos fortes no mês de novembro, provocando desfolhamento e reduzindo a área de fotossíntese, e portanto, provavelmente as reservas nutritivas, e a emissão de novas folhas.

\section{Números de folhas ativas, altura do pseudo-caule e área foliar}

0 número de folhas ativas e altura do pseudo-caule em 8/12/71: 8/2/72 e 8/4/72, e a área foliar no período de fevereiro a agosto de 1972 , foi semelhante em todos os tratamentos.

$\mathrm{O}$ número de folhas ativas entre janeiro e abril foi de 12,96 resultado semelhante as de SIMMONDS (1964), menor do que o encontrado por CHAMPION (1960) e superior ao encontrado por MATTOS (1969).

A área foliar aumentou consideravelmente até o mês de abril diminuindo a partir deste, por ocasião da emissão da inflorescência. Tal resultado concorda com as observações feitas por CHAMPION (1961) e confirmadas por SAMPAIO (1967), os quais explicam que a área foliar é caracterizada por um aumento até a terceira folha, antes do aparecimento da inflorescência. A área foliar média total, foi de $1,30 \mathrm{~m}^{2}$, para cada folha, superior a obtida por SAMPAIO (1967).

A razão de um maior número de folhas ativas e área foliar, pode atribuir-se à não incidência do «Mal de Sigatoka» (Cercos pora musae Zimm) e a ausência de concorrência das plantas em luz, nutrientes e água, o que confirma observações feitas por MATTOS (1969) para o primeiro ciclo. 


\section{Lançamento mensal de folhas}

A análise de variância para lançamento de folhas em março e abril mostrou a diferença significativa entre tratamentos, ao nível de $5 \%$ de probabilidade.

A comparação das médias dos diversos tratamentos, no mês de março, aparece no quadro 2, não sendo encontrada diferença significativa entre os diversos tratamentos.

As médias para o mês de abril aparecem no quadro 3. Sua comparação através do teste de Tukey, mostra que o tratamento $3(\mathrm{RM})$ foi superior ao tratamento $5(\mathrm{~T})$, sendo os demais tratamentos semelhantes entre si.

Quadro 2 - Comparação das médias dos diversos tratamentos para lançamentos de folhas no mês de março.

Tratamentos

4 ( $\mathrm{RMa})$

3 (RM)

$1(\mathrm{SR})$

5 (T)

$2(\mathrm{RJ})$

Lançamentos médios de folhas em março

4,00 a

4,00 a

3,75 a

3,62 a

3,50 a

Quadro 3 - Comparação das médias para lançamentos de folhas no mês de abril.

Tratamentos

Lançamentos médios de folhas em abril
3 (RM)
3,87 a
1 (SR)
3,62 a b
4 (RMa)
$3,62 \mathrm{a} \mathrm{b}$
2 (RJ)
3,25 a $b$
$5(\mathrm{~T})$
$3,00 \quad b$

\section{$\triangle 5 \%=0,84$}

O número médio de folhas emitidas em março $(3,67)$ e abril $(3,47)$, coincida com o encontrado por COMELLI (1960) e MARTINEZ (1971), para épocas favoráveis ao crescimento, diferindo no entanto do obtido pelo último autor, no mês de abril, devido a condições ambientais no decorrer do ensaio. $O$ número de dias entre emissão das folhas foi de aproximadamente 10 para 
os meses de março e abril, resultado semelhante ao obtido por SIMMONDS (1964).

\section{Número de dias do plantio ao florescimento}

A análise de variância para o número de dias do plantio ao florescimento, mostrou diferença significativa entre os tratamentos ao nível de $5 \%$ de probabilidade.

A comparação das médias através do teste de Tukey, aparece no quadro 4, mostrando diferença significativa entre os tratamentos 4 (RMa) e 3 (RM). Os tratamentos 1 (SR), 2 (RJ) e 5 (T) não diferiram entre si, nem dos demais.

Quadro 4 - Comparação das médias dos diversos tratamentos para número de dias do plantio ao florescimento.

\begin{tabular}{cc}
\hline Tratamentos & Média do número de dias para florescim. \\
\hline 4 (RMa) & $310,49 \mathrm{a}$ \\
$5(\mathrm{~T})$ & $300,83 \mathrm{a} \mathrm{b}$ \\
$2(\mathrm{RJ})$ & $290,16 \mathrm{a} \mathrm{b}$ \\
$1(\mathrm{SR})$ & $280,49 \mathrm{a} \mathrm{b}$ \\
$3(\mathrm{RM})$ & $274,49 \mathrm{~b}$ \\
\hline
\end{tabular}

$\Delta 5 \%=33,18$

Os resultados relativos a número de dias para florescimento: 274,49 dias para o tratamento $3(\mathrm{RM})$ e 280,49 dias para o tratamento 1 (SR) demonstraram precocidade das plantas matrizes, com relação a esses tratamentos. As plantas matrizes do tratamento $4(\mathrm{RMa})$ cujo comportamento esperado seria igual ao do tratamento 1 (SR) até o mês de maio, mostraram atraso relativo no seu desenvolvimento, o que pode ser atribuido ao menor crescimento de uma das parcelas ocorrido como consequência de ventos fortes no mês de novembro, provocando desfolhamento e reduzindo a área de fotossíntese e portanto, as reservas nutritivas e a emissão de novas folhas.

\section{Número mensal de florescimento}

A análise de variância para número mensal de florescimento não mostrou diferença significativa nos meses de maio, junho, agosto e setembro, porém apresentou diferença significativa ao nível de $5 \%$ de probabilidade, para 0 mês de julho.

A comparação das médias dos diversos tratamentos para o mês de julho aparece no quadro 5, revelando diferença significativa entre os tratamentos $5(\mathrm{~T})$ e $3(\mathrm{RM})$. Os demais tratamentos foram semelhantes entre si. 
Quadro 5 - Comparação das médias dos diversos tratamentos para florescimento no mês de julho.

\begin{tabular}{cc} 
Tratamentos & Média do número de florescimento em julho \\
\hline $5(\mathrm{~T})$ & $1,78 \mathrm{a}$ \\
$4(\mathrm{RMa})$ & $1,53 \mathrm{a} \mathrm{b}$ \\
1 (SR) & $1,30 \mathrm{a} \mathrm{b}$ \\
$2(\mathrm{RJ})$ & $1,10 \mathrm{a} \mathrm{b}$ \\
$3(\mathrm{RM})$ & $0,75 \mathrm{~b}$ \\
\hline
\end{tabular}

$\Delta 5 \%=0,87$

O tratamento 5 (T) teve nos meses de maio e junho, percentagem bastante menor de florescimento do que o tratamento $3(\mathrm{RM})$; grande percentagem $(54,17 \%)$ de plantas deste tratamento tiveram o seu florescimento no mês de julho, o que pode explicar a ocorrência de diferença significativa entre os dois tratamentos, em relação a florescimento no mês de julho.

\section{Número de folhas por ocasião do florescimento}

A análise de variância referente a número de folhas por ocasião do florescimento não mostrou diferença significativa entre os diversos tratamentos, o que evidencia a não influência da época de seleção do rebento sobre este fator, no presente experimento.

\section{Altura do pseudo-caule no florescimento}

A análise de variância para altura do pseudo-caule no florescimento, acusou diferença significativa ao nível de $1 \%$ de probabilidade.

A comparação das médias entre os diversos tratamentos através do teste de Tukey, aparece no quadro 6 . Houve diferença significativa entre o tratamento 1 (SR) e os tratamentos $4(\mathrm{RMa}), 5(\mathrm{~T})$ e 2 (RJ). 0 tratamento 3 (RM) mostrou diferença significativa em relação ao tratamento $2(\mathrm{RJ})$.

As alturas médias das plantas matrizes, encontradas para os tratamentos 1 (SR) e 3 (RM) foram de 2,10 e $2,08 \mathrm{~m}$, respectivamente, muito semelhantes às obtidas por SAMPAIO (1967), MATTOS, (1969) e BORGES (1971), apesar das pesquisas terem sido realizadas em regiões diferentes. 
Quadro 6 - Comparação das médias para altura do pseudo-caule no florescimento.

\begin{tabular}{cc}
\hline Tratamentos & Altura média do pseudo-caule $(\mathrm{M})$ \\
\hline 1 (SR) & $2,10 \mathrm{a}$ \\
$3(\mathrm{RM})$ & $2,08 \mathrm{a} \mathrm{b}$ \\
$4(\mathrm{RMa})$ & $1,98 \mathrm{~b} \mathrm{c}$ \\
$5(\mathrm{~T})$ & $1,92 \mathrm{~b} \mathrm{c}$ \\
$2(\mathrm{RJ})$ & $1,86 \quad \mathrm{c}$ \\
\hline
\end{tabular}

$\Delta 5 \%=0,17$

\section{Diâmetro do pseudo-caule no florescimento}

A análise de variância do diâmetro do pseudo-caule no florescimento, acusa diferença significativa entre tratamentos ao nível de $5 \%$ de probabilidade.

A comparação das médias dos diversos tratamentos através do teste de Tukey, aparece no quadro 7 .

Quadro 7 - Comparação das médias do diâmetro do pseudo-caule no florescimento.

\begin{tabular}{cc}
\hline Tratamentos & Médias do diâmetro do pseudo-caule $(\mathrm{cm})$ \\
\hline $3(\mathrm{RM})$ & $19,53 \mathrm{a}$ \\
$1(\mathrm{SR})$ & $19,08 \mathrm{a} \mathrm{b}$ \\
$4(\mathrm{RMa})$ & $18,60 \mathrm{a} \mathrm{b}$ \\
$5(\mathrm{~T})$ & $18,02 \mathrm{a} \mathrm{b}$ \\
$2(\mathrm{RJ})$ & $16,91 \mathrm{~b}$ \\
\hline
\end{tabular}
$\Delta 5 \%=2,44$

0 tratamento $3(\mathrm{RM})$ apresentou diferença significativa em relação ao tratamento $2(\mathrm{RJ})$. Os tratamentos 1 (SR), 4 (RMa), $5(\mathrm{~T})$ e 2 (RJ) foram iguais entre si.

Os valores do diâmetro do pseudo-caule das plantas matrizes dos tratamentos $3(\mathrm{RM})$ e 1 (SR) foram de 19,53 e 19,08 cm maiores que as obtidas 
por MATTOS (1969) fato que pode ser atribuido ao uso de diferentes métodos para medição, pois MATTOS (1969) efetuou as medidas a $30 \mathrm{~cm}$ do solo enquanto no presente trabalho as medidas foram tomadas a $20 \mathrm{~cm}$, do solo.

\section{Número de pencas por cacho}

Com os dados transformados em $\sqrt{ } \mathrm{x}$, a análise de variância do número de pencas por cacho mostra diferença significativa entre os tratamentos, ao nível de $5 \%$ de probabilidade.

A comparação das médias dos diversos tratamentos aparece no quadro 8, mostrando que foram todos semelhantes entre si.

Quadro 8 - Comparação das médias dos diversos tratamentos para número médio de pencas por cacho, transformados em $\sqrt{x}$

\begin{tabular}{ll}
\hline Tratamento & Número médio de pencas por cacho \\
\hline $3(\mathrm{RM})$ & $2,87 \mathrm{a}$ \\
$1(\mathrm{SR})$ & $2,83 \mathrm{a}$ \\
$4(\mathrm{RMa})$ & $2,74 \mathrm{a}$ \\
$5(\mathrm{~T})$ & $2,71 \mathrm{a}$ \\
$2(\mathrm{RJ})$ & $2,68 \mathrm{a}$ \\
\hline
\end{tabular}

$\Delta 5 \%=0,20$

Os resultados observados foram semelhantes aos obtidos por SAMPAIO (1967), MATTOS (1969) e BORGES (1971).

\section{Alfura do rebento na época do florescimento da planta matriz}

O tratamento 1 (SR) não foi considerado para efeito de cálculo uma vez que permaneceu sem rebentos durante o tempo de duração deste experimento.

A análise de variância para altura do rebento apresentou diferença significativa ao nível de $1 \%$ de probabilidade, entre os diversos tratamentos.

A comparação das médias pelo teste de Tukey, aparece no quadro 9 . 
Quadro 9 - Comparação das médias da altura do rebento na época de florescimento da planta matriz.

\begin{tabular}{lc} 
Tratamentos & Médias da altura do rebento $(\mathrm{cm})$ \\
\hline $1(\mathrm{RJ})$ & $156,87 \mathrm{a}$ \\
$5(\mathrm{~T})$ & $147,29 \mathrm{a}$ \\
$2(\mathrm{RM})$ & $45,45 \mathrm{~b}$ \\
$3(\mathrm{RMa})$ & $36,53 \mathrm{~b}$
\end{tabular}

$\Delta 1 \%=26,80$

Os tratamentos $1(\mathrm{RJ})$ e $5(\mathrm{~T})$ foram semelhantes entre si, porém mostraram diferença significativa em relação aos tratamentos $2(\mathrm{RM})$ e $3(\mathrm{RMa})$, os quais foram semelhantes entre si. A altura média do rebento selecionado em janeiro $(1 \mathrm{RJ})$ e a do maior rebento das plantas testemunhas (5 T), no momento da floração das plantas matrizes, foi de $156,87 \mathrm{~cm}$ e $147,29 \mathrm{~cm}$, respectivamente. Este desenvolvimento maior do que os atingidos pelos rebentos selecionados em março e maio, pode ser explicado pelas melhores condições de temperatura e precipitação no início do desenvolvimento do rebento nos tratamentos $(1 \mathrm{RJ})$ e $(5 \mathrm{~T})$, e por terem iniciado o seu crescimento mais cedo do que os rebentos dos tratamentos (2 RM) e 3 ( $R M a)$, sendo portanto, na época do florescimento da planta matriz, de 2 a 4 meses mais velhos.

\section{CONCLUSÓES}

Dos resultados obtidos no presente trabalho conclui-se que:

1. Os rebentos selecionados nas diferentes épocas não tiveram influência sobre o desenvolvimento vegetativo com relação a diâmetro e altura do pseudo-caule, número de folhas ativas e área foliar, porém tiveram influência sobre a emissão de menor número de folhas das plantas testemunhas no mês de abril.

2. A época de seleção do rebento teve a sua maior influência na fase da floração.

3. As plantas matrizes dos tratamentos 1 (SR) e 3 (RM) apresentaram maior florações em épocas favoráveis ao crescimento vegetativo.

4. Os tratamentos sem rebentos e aqueles em que se deixou surgir rebentos mais tardiamente influenciaram antecipando o florescimento das plantas matrizes e proporcionaram produção de cachos com maior número de pencas. 
5. Os rebentos selecionados no mês de janeiro e os mais desenvolvidos pelas plantas testemunhas, apresentaram altura superior à daqueles selecionados em março e maio, por ocasião do florescimento da planta matriz.

\section{SUMMARY}

THE INFLUENCE OF SELECTION TIME OF SUCKERS ON THE DEVELOPMENT AND PRODUCTION OF BANANA MATRIX (MUSA CAVENDISH CV NANICÃO)

The primary objetive of this study was to determine the effect of time of selection of suckers on the development of banana matriz plants (Musa cavendishii Lam. cv. Nanicão).

The treatments were as follows:

a. matrix plant without suckers;

b. matrix plant with January suckers;

c. matrix plant with March suckers;

d. matrix plant with May suckers;

e. control matrix plant: no suckers removed by pruning.

The results of this study were:

1. Fewest leaves were produced in the control matrix plants in April;

2. Time of selection of suckers affected the flowering stage more than the vegetativa stag;

3. Flowering os the matrix plant (a) with no suckers and (c, d) with March and May suckers was augmented, and production of bunches with a greater humber of hands was stimulated;

4. matrix plant with January suckers and control matrix plant attained greater height of suckers than all other matrix plants treatments.

\section{LITERATURA CITADA}

ARSCOTT, T. G., BHAMGOO, M. S. \& KARON, M. L. Irrigation investigations of the Giant Cavendish banana. II. Effects of climate on plant growth and fruit production in the Upper Aguan Valley, Honduras. Trop Agriculture, Trinidad 42 (3) : 205-209. 1965

AUPERT. B. Action du climat sur le comportement du bananier em zones tropicale et subtropicale. Fruits, Paris 26(3): 175-188. 1971.

BARKER, W. C., \& DICKSON, D. F. Early flower initiation in the banana. Nature, London 190: 1131-1132 1961

BARKER, W. G. \& STEWARD, F. C. Growth and development of the banana plant. II. The transition from the vegetative to the floral shoot in Musa acuminata cv Gros Michel. Ann. of Botany, London 26(103) : 413-423. 1962.

BARKER, W. G. Growth and development of banana plant. Gross leaf emergence. Ann. of Botany, London 33: 523-535. 1969. 
BERRILL, F. W. Plant growth and yield in the Cavendish banana (Musa cavendishii Lamb.) as affected by size and type of planting material. Od. Jour. Agric. Sci., Queenland 17(2): 69-81. 1960.

BHAN, K. C. \& MAZUNDER, P. K. Propagation trials on banana. I. Effect of size suckers and heading back on growth, maturity yield and grade of Fruit. Ind. Journ. Agric. Science New Delhi 28(2): 141-148. 1958.

BORGES, O. L. Estudio comparativo de diferentes clones de plantanos y cambures Agron. Tropical, Maracay 21(4) : 265-275. 1971.

CHAMPION, J. Aperçus sur la culture du bananier nain en Guinée Française. Fruits, Paris 6(11): 466-474. 1951 .

CHAMPION, J. Quelques indications sur les besoins en eau du bananier "nain". Fruits, Paris 15(9) : 387-400. 1960.

CHAMPION, J. Indications preliminares sur la croissance du bananier "Poyo". Fruits, Paris 16(4): 191-194. 1961.

CHAMPION, J.; LOSSOIS, P. \& MONNET, J. Le materiel végétal utilizable in plantations bananiéres. Influence sur la végétation et las redements. Fruits, Paris 17(6) : 280-283. 1962.

CHAMPION, J. Le bananier. Paris, Maisonneuvé et Larose. 1963. 264 p.

COMELLI, A. Les cultures frutières subtropicales en Israel III. Le bananier en Israel. Fruits, Paris, 15(4) : 173-184. 1960.

CORTEZ, J. V. Observaçōes do florescimento à colheita. Cultura da bananeira Musa cavendishii cultivar Nanicão. In : 1.॰ Congr. Brasil Fruit., Campinas, 1971.

CORTEZ, J. V. Cultura da bananeira. Musa cavendishii cultivar Nanica. Estudos das curvas de desenvolvimento In: $10^{\circ}$ Congr. Bras. Fruit., S. B. F., Campinas, 1971. p. 19.

CORTEZ, J. V. Contribuição para o estudo da bananeira no litoral do Estado de São Paulo. Observações sobre ciclos. Piracicaba, Escola Superior de Agricultura "Luiz de Queiroz" 1961, 46 p. (Tese de Doutoramento).

DE LANCHE, E. La phyllotaxie du bananier et ses Conséquences pour la compréhension du systéme rejetonnant. Fruits, Paris 16(9): 429-44. 1961.

GREEN, G. C. \& KUHNE, F. A. Growth of the banana plant in relation to winter air temperature fluctuations Agroplantae Pretoria 1: 157-162. 1960.

GREEN, G. C. \& KUHNE, F. A. Research note. The response of banana foliar growth to widely fluctuating air temperatures. Agroplante, Pretoria 2: 105-107. 1970.

GUYOT, H. \& FOUQUE, A. Le Poyo. Un bananier cultivé en Guadeloupe. Observar tions sur sa végétation. Fruits, Paris 9(2) 60-67. 1954.

HASSELLO; H. N. An evaluation of the circunference of the pseudostem a growth index for the "gros Michel" banana. Trop. Agriculture, Trinidad, 39(1) : 57-63. 1692.

KERVEGANT, D. Le bananier et son explotation. Paris Socièté d'Editions Geographiques. Maritimes et Coloniales. 1935, 578 p.

LASSOUDIERE, A. \& CHARPENTIER, J. M. La vitesse de sortie des feuilles du bananier cultivar "Poyo". Fruits, Paris (6) : 409-419 1971.

LOSSOIS, P. Recherche d'une méthode de prévision des récoltes en culture bananière. Fruits, Paris 18(6) : 293-293. 1963.

MARTINEZ, J. A. Lançamentos mensais de folhas de bananeira. In $10^{\circ}$ Congr. Bras. Frut., S.B.F., Campinas 1971, p. 18. 
MATTOS, J. R. DE. Aspectos da densidade do bananal no Litoral do Estado de São Paulo. Piracicaba, Escola Superior de Agricultura "Luiz de Queiroz". 1969. 71 p. (Tese de doutoramento).

MOREZ, $H$. Les effects de la conservation d'une portion de faux tronc attenant aux rhizomes plantés sur la sortier et le développement des rejets (bananiers Poyo). Fruits, Paris 15(9) : 423-424. 1960.

MOREZ, H. \& GUILLEMOT, J. Le choix du matérial végétal de plantation en bananiers. Influence de la conservation d'une partie de faux tronc attenant au rhizome sur la croissance des rejets. (bananiers "Pyo"). Fruits, 16(10) : 517-520. 1961.

MURRAY, D. B. The effects of deficiencies of the major nutrients on growth and leaf analysis of the banana. Trop. Agriculture, Trinidad 37(2): 97-106. 1960.

RANZANI, G., FREIRE, O. \& KINJO, R. Cartas do solo do Municipio de Piracicaba. Piracicaba, Escola Superior de Agricultura "Luiz de Queiroz", 196685 p. (mimeografado).

ROCHA, G. F. R. \& FRANCIOSI, R. Métodos de propagación del platano.Turrialba, Costa Rica, 13(2): 121-123. 1963.

RODRIGUES, A. \& SOUZA, A. T. DE. Sobre a época de seleção dos rebentos da bananeira (Musa nana Lour.) seu desenvolvimento e frutificação na Ilha de Agron. Lusitana. Oieiras 9(2): 193-248 - 1947.

SAMPAIO, V. R. Banana. Estudo comparativo das variedades "Nanicão" e "Nanica" no Litoral do Estado de São Paulo. Piracicaba, Escola Superior de Agricultura "Luiz de Queiroz" 1967. 71 p. (Tese de Doutoramento).

SIMMONDS, N. W. Bananas. $1 .^{*}$ ed. (3* imp) London. Logmans. 1964. 466 p. 1960.

SMIRIN, S. Banana Growing in Israel. Trop. Agriculture, Trinidad 37(2) : 87-95. 1960.

TRE LEASE, S. F. Night and day rates of elongation of banana leaves The Phillipp. Jour. of Science, Manila 23:85-96. 1923.

TURNER, D. W. Effects of climate on rate of banana leaf production Trop. Agriculture, Trinidad 48(3): 283-287. 1971 .

WARDLAW, C. W. \& GUIRE. L. P. Mc. Cultivation and diseases of the banana in Brazil Trop. Agriculture, Trinidad X (7): 192-197. 1933.

WARDLAW, C. W. Banana disease including plantains and abaca. London-Longmans, $1961,648 \mathrm{p}$. 
